\title{
Application of Different Methods to Determine Urease Activity in Enzyme Engineering Experiment and Production
}

\author{
Fenghong Liu ${ }^{1}$, Xianhao Cheng ${ }^{2 *}$, Jing Miu ${ }^{3}$, Xinjun $\mathrm{Li}^{1 *}$, Runyang Yin ${ }^{1}$, Jiahui Wang ${ }^{1}$, Yanping Qu ${ }^{1}$ \\ ${ }^{1}$ College of Chemical and Biological Engineering, QILU Institute of Technology, Jinan, Shandong 250200. \\ ${ }^{2}$ College of Agriculture, Ludong University, Yantai, Shandong, 264001. \\ ${ }^{3}$ College of Life Sciences, Ludong University, Yantai, Shandong, 264001.
}

\begin{abstract}
The determination of urease activity is one of the important projects in 《Enzyme engineering experiment》 and production. In the paper, the urease activity of soybean was determined by $\mathrm{pH}$ increment method, titration method and Nash reagent method, and the three methods were compared. The results showed that the urease activity of the same sample measured by $\mathrm{pH}$ increment method, titration method and Nash reagent method was not equal in value and could not be used mutually, and the urease activity of the same sample measured by Nash reagent method was the highest. The same experimental project adopts a variety of methods to improve students ' interest in learning, improve students' data analysis ability, and provide a better way to cultivate applied and innovative talents.
\end{abstract}

\section{Introduction}

Enzyme engineering is the main course of biological engineering. It is an important subject to study the production and application of enzymes. It integrates the knowledge of microbiology, biochemistry, fermentation engineering, biological separation engineering and other disciplines ${ }^{[1]}$. It is very comprehensive and applied. Therefore, the role of enzyme engineering experiments is very important.

China's "Feed Soybean" standard (GB10380-89) ${ }^{[2]}$ stipulates: "Feed soybeans should be heated and used, and urease activity should not exceed $0.4 \mathrm{NH}_{3}, \mathrm{mg} /(\mathrm{g} \mathrm{min}) "$; Our country's "soybean cake for feed" standard (GB10379$89)^{[3]}$ and "soybean meal for feed" standard (GB10380$89)^{[2]}$ stipulate that "urease activity of soybean cake and soybean meal shall not exceed $0.4 \mathrm{NH} . \mathrm{mp} /(\mathrm{g} \mathrm{min}) "$. Therefore, the determination of urease activity also plays a very important role in production.

Urease activity determination is an important experimental project in enzyme engineering experiment course. Traditional experimental courses generally use $\mathrm{pH}$ value-added method or titration or Nessler ' $\mathrm{s}$ reagent method. Students will get a set of corresponding experimental results in the determination. The experimental process and data processing cannot effectively exercise the comprehensive ability of students ${ }^{[4,5]}$. Taking the experimental teaching of enzyme engineering in Qilu University of Technology as an example, in order to improve the teaching quality and better cultivate a group of applied and innovative talents with strong practical ability and adapt to the needs of social development, this paper explores the determination method of urease activity in the experimental course of enzyme engineering.

\section{Materials and methods}

\subsection{Experimental materials}

Soybean powder: raw soybeans are crushed and sieved with 60 mesh $(0.250 \mathrm{~mm})$ standard sieve.

\subsection{Chemical reagents}

The reagents used in this experiment are all analytically pure (AR), and the experimental water is distilled water, phosphate buffer, urea buffer, $0.1 \mathrm{~mol} / \mathrm{L}$ sodium bicarbonate solution and $1 \mathrm{~mol} / \mathrm{L}$ sulfuric acid solution.

\subsection{Urease activity determination method}

\subsection{1pH increment method}

Experimental principle: the ground sample is mixed with urea buffer solution, and urea is hydrolyzed by urease to produce ammonia, which changes the $\mathrm{pH}$ value of the solution, The degree of change is related to the urease activity, so the difference between the sample and the blank solution can be used to express the urease activity in $\Delta \mathrm{pH}$ value $\mathrm{e}^{[\mathrm{G}]}$.

Calculation formula : $\mathrm{UA}=\mathrm{pH}_{1}-\mathrm{pH}_{0}$

In the formula:

UA-urease activity, $\mathrm{pH}$;

$\mathrm{pH}_{1}-\mathrm{pH}$ value of sample solution after urea is

Corresponding author: ${ }^{2 *}$ chengxianhao@sohu.com; ${ }^{1 *} 928878031 @ q q . c o m$ 
decomposed by sample;

$\mathrm{pH}_{0}$ - $\mathrm{pH}$ value of blank sample solution.

\subsubsection{Titration method}

Experimental principle: the sample was mixed with neutral urea buffer and kept at $30 \pm 0.5^{\circ} \mathrm{C}$ for $30 \mathrm{~min}$, Urease in the sample catalyzed urea hydrolysis to produce ammonia, which was neutralized with excessive hydrochloric acid and then dripped back with sodium hydroxide standard solution until the $\mathrm{pH}$ value of the solution was 4.7. Urease activity is expressed in milligrams of ammonia nitrogen produced per gram of sample at $30 \pm 0.5^{\circ} \mathrm{C}$ per minute, and the unit is $\mathrm{NH}_{3} \mathrm{mg} / \mathrm{g} \cdot \mathrm{min}$.

Operation method:(1)The calibration of sodium hydroxide standard solution is that $0.6 \mathrm{~g}$ potassium hydrogen phthalate ( accurate to $0.0001 \mathrm{~g}$ ) is dried to constant weight at $105 \sim 110^{\circ} \mathrm{C}$, dissolved in $50 \mathrm{~mL}$ water, and added two drops of phenolphthalein indicator. The solution is titrated to pink with the prepared sodium hydroxide standard solution. At the same time do blank test. (2) Weigh $0.2000 \mathrm{~g}$ sample for UA determination, transfer it into a colorimetric tube, add $10 \mathrm{~mL}$ urea buffer, cover it immediately and shake it violently. After being placed in a constant temperature water bath at $30 \pm 0.5^{\circ} \mathrm{C}$ for $30 \mathrm{~min}$, immediately add $10 \mathrm{~mL}$ of $0.1 \mathrm{~mol} / \mathrm{L}$ hydrochloric acid, quickly cool to $20^{\circ} \mathrm{C}$, transfer all the contents of the colorimetric tube into a beaker, rinse the colorimetric tube with water for 2 3 times, and immediately titrate with standard sodium hydroxide solution to $\mathrm{pH}=4.7$. In addition, take the colorimetric tube for blank test, and add $10 \mathrm{~mL}$ urea buffer and $10 \mathrm{~mL}$
$0.1 \mathrm{~mol} / \mathrm{L}$ hydrochloric acid. Weigh the sample equivalent to the above sample amount, quickly add it into the colorimetric tube, immediately cover it like a colorimetric tube and shake it violently, accurately keep it in a constant temperature water bath of $30 \pm 0.5^{\circ} \mathrm{C}$ for $30 \mathrm{~min}$, cool it to $20^{\circ} \mathrm{C}$, transfer all the contents of the colorimetric tube into a beaker, rinse the colorimetric tube with water for 2 3times, and titrate it with standard sodium hydroxide solution to $\mathrm{pH}=4.7$.

Calculation formula: $\mathrm{U}=14 \times \mathrm{c}\left(\mathrm{V}_{0}-\mathrm{V}\right) / 30 \times \mathrm{m}$

In the formula:

U-urease activity expressed by milligram of nitrogen released per gram of soybean product per minute;

c-molar concentration of sodium hydroxide standard solution $(\mathrm{mol} / \mathrm{L})$;

$\mathrm{V}_{0}$-volume of standard sodium hydroxide solution consumed in blank test $(\mathrm{mL})$;

V-the volume of standard sodium hydroxide solution consumed by the test sample $(\mathrm{mL})$;

$\mathrm{m}$-mass of sample $(\mathrm{g})^{[7]}$.

\subsubsection{Nash reagent method}

Experimental principle: rease catalyzed hydrolysis of urea to ammonia and carbon dioxide, and the optimum reaction $\mathrm{pH}$ was 7.0. The reaction formula is $(\mathrm{NH})_{2} \mathrm{CO}+\mathrm{H}_{2} \mathrm{O} \rightarrow 2 \mathrm{NH}_{3}+\mathrm{CO}_{2}$. Ammonia reacts with Nessler's reagent to form a yellow complex, and its absorbance is directly proportional to ammonia concentration, so it can be used to determine the activity of enzyme. The reaction formula is $\mathrm{NH}_{3}$ $\mathrm{H}_{2} \mathrm{O}+2 \mathrm{~K}_{2} \mathrm{HgI}_{4}+3 \mathrm{KOH} \rightarrow \mathrm{HgO} \cdot \mathrm{HgNH}_{2} \mathrm{I}+7 \mathrm{KI}+3 \mathrm{H}_{2} \mathrm{O}$.

$$
\text { Urease activity }\left(U m L^{-1}\right)=\frac{\left(A_{3}-A_{1}\right) \times \text { Micromolar number of NH3 in standard tube } \times n}{\left(A_{2}-A_{1}\right) \times 5 \min \times \text { ML number of enzyme samples }(V)}
$$

In the formula:

$\mathrm{n}$ is the dilution multiple of enzyme sample ${ }^{[8]}$.

Tab1. The step of Nash reagent method

\begin{tabular}{c|c|c|c}
\hline Step/Tube number & 1 & 2 & 3 \\
\hline (1)properly diluted enzyme solution to be tested $(\mathrm{mL})$ & 0 & 0 & 1.00 \\
(2)Standard ammonium sulfate solution $(\mathrm{mL})$ & 0 & 0.3 & 0 \\
(3)distilled water $(\mathrm{mL})$ & 2.00 & 1.70 & 1.00 \\
(4) $1 \mathrm{~mol} / \mathrm{L} \mathrm{H}_{2} \mathrm{SO}_{4}(\mathrm{~mL})$ & 1.00 & 1.00 & 0 \\
\hline
\end{tabular}

(5) Balance in constant temperature water bath at $25^{\circ} \mathrm{C}$ for $5 \mathrm{~min}$.

$$
\text { (6) } 3 \% \text { urea }(\mathrm{mL})
$$

1.00

1.00

1.00

(7) Start timing from adding urea to the sample tube, react accurately for $5 \mathrm{~min}$, and immediately add $1 \mathrm{moL} / \mathrm{L} \mathrm{H} 2 \mathrm{SO} 4$ to the sample tube (No.3 tube) to terminate the reaction.

(8) Take another three clean test tubes, and develop colors corresponding to the above reaction solutions.

$$
\begin{aligned}
& \text { (1) reaction solution }(\mathrm{mL}) \\
& \text { (2) distilled water }(\mathrm{mL}) \\
& \text { (3) Nessler's reagent }(\mathrm{mL})
\end{aligned}
$$

0.50

0.50

(9) After each tube is well mixed, test with spectrophotometer within $30 \mathrm{~min}$. 


\section{Results and Dicussion}

\subsection{Difference of three methods for determination of urease activity}

\subsection{1 $\mathrm{pH}$ value-added method \\ $\mathrm{pH}_{1}=7.91 \quad \mathrm{pH}_{0}=6.25 \quad \mathrm{UA}=1.66$}

\subsubsection{Titration method}

$\mathrm{U}=14 \times 0.1(34.6-6) / 30 \times 0.025=53.3867 \mathrm{U} / \mathrm{mL}^{-1}$

\subsubsection{Nessler's reagent method}

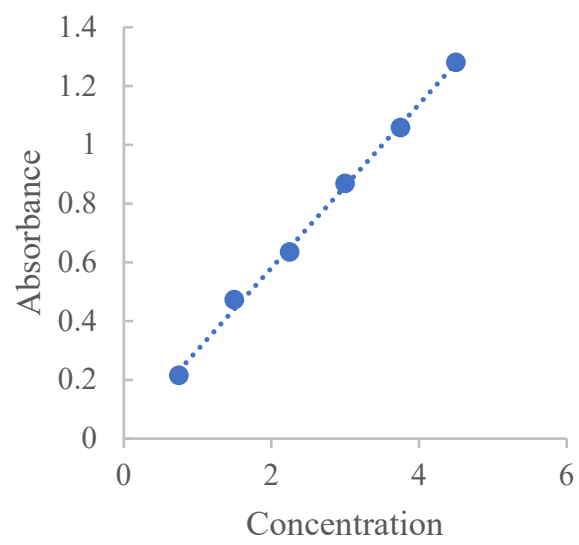

Fig.1 Standard curve of Nessler's reagent method The urease activity was $383.15 \mathrm{U} / \mathrm{mL}^{-1}$.

In China, the national standard stipulates that the determination method of urease activity in soybean, soybean cake and meal is titration. However, in actual production, in order to achieve the purpose of simple and easy determination method and rapid guidance for production, $\mathrm{pH}$ value-added method is generally used for the determination of urease activity in soybean and its byproducts. As mentioned above, the three methods have different experimental principles, experimental procedures, results and numerical units in the determination process. Among them, the determination results of the Nessler reagent method were relatively large ${ }^{[9]}$. Therefore, in the actual production, the determination results of the three methods cannot be directly substituted for each other. When the soybean urease activity is expressed or the specific limit requirements are put forward, the determination method should be clearly used.

\subsection{The relationship among three methods for determination of urease activity}

Although there are many differences among $\mathrm{pH}$ valueadded method, titration method and Nash reagent method, there are also certain connections. The measured data were calculated with CORREL function in Excel, and the correlation reached 0.996 . The change rules of the measurement results of the same three methods are basically the same, and the three can be numerically replaced by calculation. In order to achieve the purpose of using simple detection methods, it can be inferred that the more accurate determination results can be determined by more complex detection methods ${ }^{[10]}$.

\subsection{Advantages of three methods used in 《Enzyme engineering experiment》 and production}

The urease activity of the same sample measured by $\mathrm{pH}$ increment method, titration method and Nessler 's reagent method is not equal in value and cannot be used in each other, and the urease activity of the same sample measured by Nessler 's reagent method is the highest. The same experimental project using a variety of methods can improve students' interest in learning and data analysis ability, and better guide the production of urease detection

\section{Conclusion}

Although the data of urease activity in soybean measured by $\mathrm{pH}$ value-added method, titration method and Nessler 's reagent method are quite different and cannot be directly used, according to the relationship between them, certain conditions can be established and a simple and feasible method can be found to replace each other, so as to realize the simple and complicated experimental process, which can not only improve students' interest in learning and data analysis ability, but also quickly and efficiently guide the actual production.

\section{Acknowledgements}

Research on comprehensive utilization and pilot production of secondary fruit of Wudi jujube, provincial key R \& D plan in 2019 (tackling key scientific and technological problems for public welfare), (Project No. 2019GSF107083)

Research on the theory and practice of the deep integration course of specialty and innovation based on the cultivation of students' innovation and entrepreneurship--Taking bioengineering as an example(JG201918)

\section{References}

1. XJ Zh, JF Zh, JJ Zh. Expansion of

《Enzyme engineering》 confirmatory

experiments $[\mathrm{J}]$.Technological and economic journals, 2016(23): 149 .

2. Ministry of Agriculture of the People's Republic of China. GB 10379-1989 method for determination of urease activity in soybean products [S]. Beijing: China Standards Press (2008).

3. Ministry of Agriculture of the People's Republic of China. GB 10380-1989 method for determination of urease activity in soybean products [S]. Beijing: China Standards Press (2008). 
4. FZh Zh, JH L, J L. Construction and practice of 'trinity' experimental teaching system of enzyme engineering in universities for nationalities $[\mathrm{J}]$. Chemical engineering and equipment, 2015(05): 233-234.

5. H H, SF D, Q B. 《Enzyme engineering》 theory and experimental teaching reform [J].Journal of Tongling Vocational and Technical College, 2015,14(04): 54-56.

6. QH Y, L Sh, JF Zh.Comparison of different methods for determination of soybean urease activity [J].Feed wide angle, 2008 (21): 30-32.

7. YL Y, DH Z, NY Zh.Comparative study on determination methods of soybean urease activity $[\mathrm{J}]$. Breeding and feed, 2005 (06): 23-25.

8. DK Zh, Y L, XL M. Extraction of soybean urease and its influencing factors [J].Soybean Science, 2008 (04): 704-707.

9. JJ H. Design and practice of comprehensive experimental project of enzyme engineering $[\mathrm{J}]$. Modern agricultural science and technology, 2020 (03) : 247-250.

10. ChSh Q, LM J, ChZh Zh. Exploration on experimental teaching reform of enzyme engineering $[\mathrm{J}]$. Journal of Dalian University for Nationalities, 2015,17 (05): 519521. 